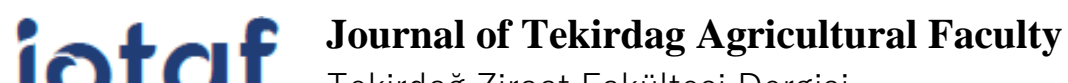

\section{Sultani Çekirdeksiz Üzüm Çeşidinde Farklı Kurutma Yöntemlerinin Kurutma Kinetiği, Enerji Tüketimi ve Ürün Kalitesi Açısından İncelenmesi}

\author{
Examination of Different Drying Methods in Sultana Seedless Grapes In Terms of Drying \\ Kinetics, Energy Consumption and Product Quality
}

\section{Ersin KARACABEY ${ }^{1 *}$, Türkan AKTAŞ ${ }^{2}$, Levent TAŞERİ ${ }^{1}$, Gamze UYSAL SEÇKİN ${ }^{1}$}

\section{$\ddot{\mathbf{O} z}$}

Bu çalışmada Sultani çekirdeksiz üzüm örnekleri herhangi bir önişlem uygulaması yapılmadan mikrodalga ve sıcak hava yöntemi kullanılarak farklı sıcaklık ve güç değerlerinde kurutulmuş, yönteme bağlı olarak kurutma kinetikleri ve enerji tüketim değerleri ortaya konulmuştur. Sicak hava ile kurutma denemeleri 50,60 ve $70{ }^{\circ} \mathrm{C}$ sıcaklık ve $1 \mathrm{~m} \mathrm{~s}^{-1}$ hava hızı değerinde ve mikrodalga ile kurutma denemeleri 180 ve $270 \mathrm{~W}$ güç değerlerinde gerçekleştirilmiştir. Deneysel verileri değerlendirmek için literatürde önerilmiş olan Wang ve Singh, HendersonPabis, Newton ve Logaritmik ince tabaka kurutma modelleri kullanılmış ve bu modeller arasında Wang ve Singh modelinin, hem sıcak havalı kurutma hem de mikrodalga kurutma yöntemleri için sultani çekirdeksiz üzümün kuruma davranışını temsil eden en iyi model olduğu saptanmıştır. Sıcak hava yönteminde sıcaklık yükseldikçe fenolik madde miktarları ve kahverengileşme indeksi değerleri yükselmiştir. $200 \mathrm{~g}$ üzüm örneklerinde yapılan denemelerde ürün ilk neminin $\% 75^{\prime}$ den $\% 20$ seviyesine düşürülmesinde sıcak hava ile kurutma uygulamasında en düşük kurutma süresi $70^{\circ} \mathrm{C}^{\prime}$ de 10 saat ve mikrodalga ile kurutma yönteminde $270 \mathrm{~W}$ uygulama gücünde 35 dakika olarak bulunmuştur. En düşük özgül enerji tüketimi; sıcak hava uygulamasında $70{ }^{\circ} \mathrm{C}$ 'de $19,15 \mathrm{kWh} \mathrm{kg}^{-1}$ ve mikrodalga ile kurutma yönteminde $270 \mathrm{~W}$ uygulama gücünde $1,52 \mathrm{kWh} \mathrm{kg}^{-1}$ olarak elde edilmiştir.

Anahtar Kelimeler: Sultani çekirdeksiz üzüm, kurutma, mikrodalga, sıcak hava, kurutma kinetiği, enerji tüketimi

\section{Abstract}

Sultana Seedless grape samples were dried using hot air and microwave methods in different temperature and power levels with untreated conditions and drying kinetics and energy consumption values based on method were revealed in this study. Hot air drying experiments in electric forced convection oven were conducted in temperatures of 50,60 and $70{ }^{\circ} \mathrm{C}$ with $1 \mathrm{~m} \mathrm{~s}^{-1}$ air velocity. Microwave drying experiments were conducted in 180 and $270 \mathrm{~W}$ power levels. Wang and Singh, Henderson-Pabis, Newton and Logaritmik thin layer drying methods offered in the literature were used to evaluate experimental values and it was determined that Wang and Singh model represents the drying characteristics of Sultana seedless grape as the best for both methods. Phenolic content and browning index increased with temperature rise in hot air method. Minimum drying time was obtained as 10 hours in $70^{\circ} \mathrm{C}$ hot air drying and 35 minutes in $270 \mathrm{~W}$ microwave power level for decreasing moisture content of

\footnotetext{
1*Sorumlu Yazar/Corresponding Author: Ersin Karacabey, Bağc1lık Araştırma Enstitü Müdürlüğü, Tekirdağ. E-mail: ersin.karacabey@tarimorman.gov.tr (iD) OrcID: 0000003-4166-1553

${ }^{2}$ Türkan Aktaş, Tekirdağ Namık Kemal Üniversitesi, Ziraat Fakültesi, Biyosistem Mühendisliği Bölümü, Tekirdağ. E-mail: taktas@nku.edu.tr (DD OrcID: 00000001-9977-859X.

${ }^{1}$ Levent Taşeri, Bağcılık Araştırma Enstitü Müdürlüğü, Tekirdağ. E-mail: levent.taseri@ tarimorman.gov.tr (D) OrcID: 0000-0002-4494-9125.

${ }^{1}$ Gamze Uysal Seçkin, Bağcılık Araștırma Enstitü Müdürlüğü, Tekirdağ. E-mail: gamze.uysalseckin@tarimorman.gov.tr (iD) OrcID: 00000-0002-2117-075X Atıf/Citation: Karacabey, E, Aktaş, T, Taşeri, L,Seçkin Uysal, G. Sultani çekirdeksiz üzüm çeşidinde farklı kurutma yöntemlerinin kurutma kinetiği, enerji tüketimi ve ürün kalitesi açısından incelenmesi.

Tekirdağ Ziraat Fakültesi Dergisi, 17(1), xx-xx.
} 
$200 \mathrm{~g}$ grape samples from $75 \%$ (w.b.) to $20 \%$ (w.b.). Minimum specific energy consumption was determined as $19,15 \mathrm{kWh} \mathrm{kg}^{-1}$ in $70{ }^{\circ} \mathrm{C}$ hot air drying and $1,52 \mathrm{kWh} \mathrm{kg}^{-1}$ in $270 \mathrm{~W}$ microwave power level.

Keywords: Sultana seedless grape, drying, microwave, hot air, drying kinetics, energy consumption 


\section{Extendend Summary}

Raisin is an important food product with vitamin, mineral and phenolic content. Drying time and energy consumption based on energy source is very important in drying period. Sultana Seedless grape samples were dried using hot air and microwave methods in different temperature and power levels with untreated conditions and drying kinetics and energy consumption values based on method were revealed in this study. Hot air drying experiments in electric forced convection oven were conducted in temperatures of 50, 60 and $70{ }^{\circ} \mathrm{C}$ with $1 \mathrm{~m} \mathrm{~s}^{-1}$ air velocity. Microwave drying experiments were conducted in 180 and $270 \mathrm{~W}$ power levels. Wang and Singh, Henderson-Pabis, Newton and Logaritmik thin layer drying methods which are offered in the literature were used to evaluate experimental values. Comparison of models was made by using model efficiency, chi-square $\left(\chi^{2}\right)$ and root mean square error statistical parameters. It was determined that Wang and Singh model represents the drying characteristics of Sultana seedless grape as the best for both hot air and microwave drying methods.

It was observed that there is an important relation between product amount and power level in microwave drying method. For instance in 16,5 g grape sample product moisture was decreased from $75 \%$ (w.b.) to $29 \%$ (w.b.) in one hour without discoloration in $90 \mathrm{~W}$ while this power level was insufficient in drying of $200 \mathrm{~g}$ samples. Besides, no unfavorableness was observed in 70-75\% part of drying period although there are some negative features such as blast and discoloration with caramelisation in final product in microwave drying method. Moisture content in this point decreased till 45-50\%.

Phenolic content and browning index increased with temperature rise in hot air method. Rise in browning index shows browning in color of raisins increases with temperature. Significant decrease in drying time and energy consumption for unit product with temperature rise occurred in hot air drying method. Minimum drying time was obtained as 10 hours in $70{ }^{\circ} \mathrm{C}$ hot air drying and 35 minutes in $270 \mathrm{~W}$ microwave power level for decreasing moisture content of $200 \mathrm{~g}$ grape samples from $75 \%$ (w.b.) to $20 \%$ (w.b.). Minimum specific energy consumption was determined as $19,15 \mathrm{kWh} \mathrm{kg}^{-1}$ in $70{ }^{\circ} \mathrm{C}$ hot air drying and $1,52 \mathrm{kWh} \mathrm{kg}^{-1}$ in $270 \mathrm{~W}$ microwave power level. 
Tarımsal ürünlerin kurutulmasında amaç, yaş ürünlerdeki serbest suyu uzaklaştırarak, ürünlerde meydana gelebilecek biyokimyasal reaksiyonları ve mikroorganizmaların ürünü bir besin kaynağı olarak kullanıp büyümelerini durdurmaktır. Ayrıca, kurutulmuş ürünlerin hacimlerinde ve ağırlıklarında büyük oranda küçülme sağlandığı için bu yöntem, taşıma ve depolama maliyetlerini de azaltmaktadır. Günümüzde ticari olarak kullanılan kurutuculardan hiçbiri tam olarak hem en ekonomik ve hem de en kaliteli kurutma işlemini bir arada sağlayamamaktadır. Her yöntem enerji tüketimi, kurutma maliyeti ve ürünlerdeki kalite değişimi açısından sınırlama veya eksikliklere sahiptir (Tarhan ve ark., 2007).

Farklı yöntemler kullanılarak elde edilen sonuçların değerlendirilmesinde kimyasal yönden ön plana çıkan bir yöntemin fiziksel veya duyusal analizlerde olumsuz özelliklere sahip olabileceği daha önce yapılan çalışmalarda görülmektedir. Bu nedenle ürün kalitesi ile birlikte kurutma süresi ve enerji maliyetlerinin birlikte kapsamlı şekilde değerlendirilmesiyle en uygun kurutma yönteminin önerilmesi önemlidir.

Farklı kurutma yöntemlerinin kombine kullanımına yönelik çalışmalarda kurutma karakteristikleri ve ürün kalitesi açısından önemli sonuçlar çıktığı görülmektedir. Bu tarz sistemlerde çoğunlukla hangi kurutma yönteminin kurutma sürecinin ne kadarlık bölümünde ve hangi sırayla yer alacağı önem taşımaktadır.

İçermiş olduğu vitamin, mineral ve fenolik maddeler ile kuru üzüm önemli bir gıda ürünüdür. Kurutma sürecinde ise kurutma süresi ve kullanılan enerji kaynağına bağlı olarak gerçekleşen enerji tüketimi oldukça önemlidir. Farklı kurutma yöntemlerinin üzüm kurutmada kullanımında kurutma süresi, enerji tüketimi ve ürün kalitesinin belirlenmesine yönelik çeşitli araştırmalar mevcuttur. Elde edilen son ürünün kalitesinin belirlenmesine yönelik çalışmalarda üzüm içerisindeki insan sağlığı açısından önem taşıyan maddelerin miktarındaki değişimler incelenmiştir.

Son yıllarda tarımsal ürünlerden uzaklaştırılan nem miktarının arttırılarak kurutma süresinin kısaltılması için mikrodalga ile kurutma yöntemine giderek artan bir ilgi oluşmuştur. Bu kurutma yöntemi daha yüksek kuruma hızı, daha kısa kuruma süresi, düşük enerji tüketimi ve daha yüksek ürün kalitesi sağlama avantajlarına sahiptir. En düşük ekonomik girdiyle kaliteli ürün elde ederek ve enerji tüketimini düşürerek kurutma süreçlerinin iyileştirilmesi modern kurutmanın bir hedefi haline gelmiştir. Tek bir yöntemle bu hedefe ulaşılamayacağından mevcut yöntemlerin kombine kullanımı düşünülmelidir (Kassem ve ark., 2011).

Farklı kurutma yöntemlerinin kombine olarak kullanımını içeren çalışmalardan birinde Kassem ve ark. (2011), mikrodalga ve sıcak hava ile kurutma yöntemlerinin Sultani çekirdeksiz üzüm çeşidinde kuruma karakteristikleri üzerine etkilerini karşılaştırmalı olarak incelemiştir. Belirli bir mikrodalga güç aralığında güç seviyesini arttırmanın kurutma işlemini hızlandırarak süreyi kısalttığını belirtmiştir. Ortalama enerji

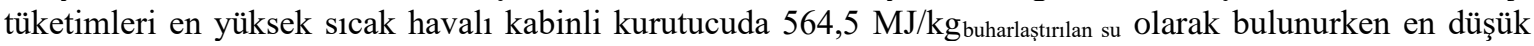
enerji tüketimi sıcak havalı kabinli kurutucuyla tamamlanan mikrodalga kurutma sisteminde 320,6 $\mathrm{MJ} / \mathrm{kg}_{\text {buharlaştrrilan su }}$ olarak bulunmuştur.

Karaaslan ve ark. (2017), Sultani üzüm çeşidinde konvektif kurutma (100, 150 ve $\left.200{ }^{\circ} \mathrm{C}\right)$, mikrodalga kurutma $(180,540$ ve $720 \mathrm{~W})$ ile konvektif ve mikrodalga kombine kurutmanın $\left(180 \mathrm{~W}-100{ }^{\circ} \mathrm{C}, 360 \mathrm{~W}-100\right.$ ${ }^{\circ} \mathrm{C}$ kurutma süresi ve kuruma hızı üzerine etkilerini araştırmıştır. Kurutma verilerini Midilli-Kucuk, Weibull dağılımı, logistic ve Alibas Eşitlik modellerine uygulayarak gözlenen ve tahmin edilen nem oranları arasındaki ilişskiyi gösteren katsayılara göre karşılaştırmalarını yapmıştır. Weibull dağılım modeli $540 \mathrm{~W}-100{ }^{\circ} \mathrm{C}$ kombine uygulaması dışındaki tüm kurutma denemeleri için en iyi tanımlayıcı model ve Alibas modeli ise 540 $\mathrm{W}-100{ }^{\circ} \mathrm{C}$ kombine kurutma denemesi için en iyi tanımlayıcı model olarak bulunmuştur.

Almeida ve ark. (2013) Crimson çekirdeksiz üzüm çeşidinden kuru üzüm üretiminde farklı kurutma yöntemlerinin etkisini inceledikleri çalışmada bir güneş fırını içerisinde doğrudan güneşe maruz bırakma ile $50{ }^{\circ} \mathrm{C}$ ve $60{ }^{\circ} \mathrm{C}$ sıcaklıklarda sabit hava hızında kurutma yöntemlerini denemişlerdir. Elde edilen ürünle ilgili fiziksel, kimyasal ve duyusal değerlendirmeleri gerçekleştirmiştir. Sonuçta fiziksel ve kimyasal değerlendirme yönünden yapılan testlerde farklı kurutma yöntemlerinin önemli farklılık göstermediğini ortaya koymuşlardır. En önemli fark olarak konvektif kurutma yönteminin daha kısa sürelerde daha düşük nem seviyesine ulaşma şeklinde olduğunu ve bunun ekonomik yönden önemli sonuç olduğunu belirtmiştir. Duyusal analizlerde ise elde edilen ürünün pazarda ulaşılabilen ticari ürünle benzer özelliklere sahip bulunduğunu ortaya koymuştur. 


\section{Materyal ve Yöntem}

Bu çalışmada farklı kurutma yöntemlerinin uygulandığı denemelerde Sultani Çekirdeksiz üzüm çeşidi kullanılmıştır. Tüm kurutma denemesi tekerrürlerinde yaklaşık $200 \mathrm{~g}$ yaş üzüm örneği kullanılmıştır. Sıcak hava ile kurutma yönteminde laboratuvar tipi $45 \mathrm{cmx} 45 \mathrm{~cm}$ ebadında 10 adet tepsiye sahip, sicaklık ve hava sirkülasyon kontrollü, ağırlık tartım özelliği olan kurutma sistemi kullanılmıştır.
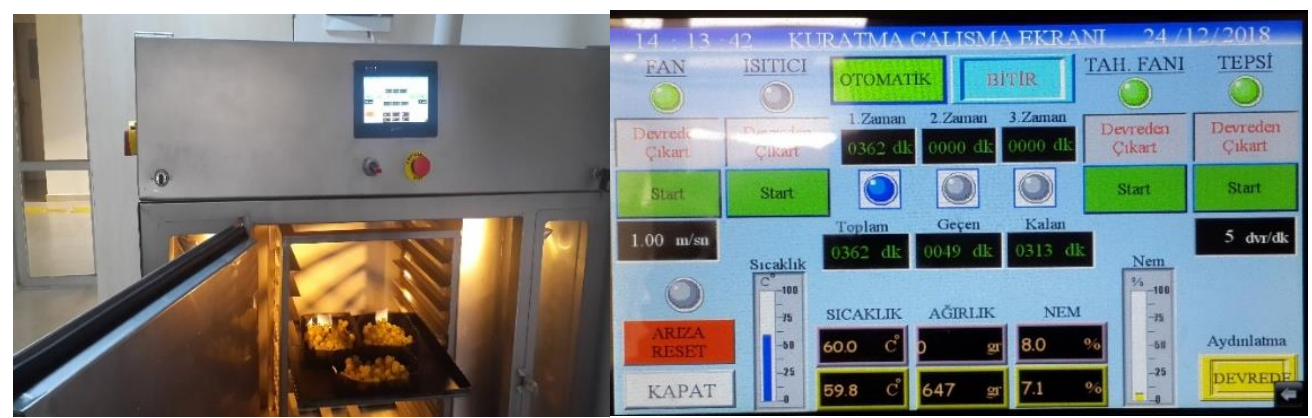

Şekil 1. Elektrikli sıcak hava fırını ve kontrol ekranı

Figure 1. Electrical hot air oven and control monitör

Mikrodalga kurutma yönteminde ise Beko marka, $2450 \mathrm{MHz}$ frekanslı, 800 W'lık enerji değerli, 19 litrelik iç hacimli, döner tablalı mikrodalga fırın kullanılmıştır. Bu fırın her 5 sn.de ağırlık azalışını otomatik olarak kaydeden bir tartım sistemine sahiptir (Şekil 2).

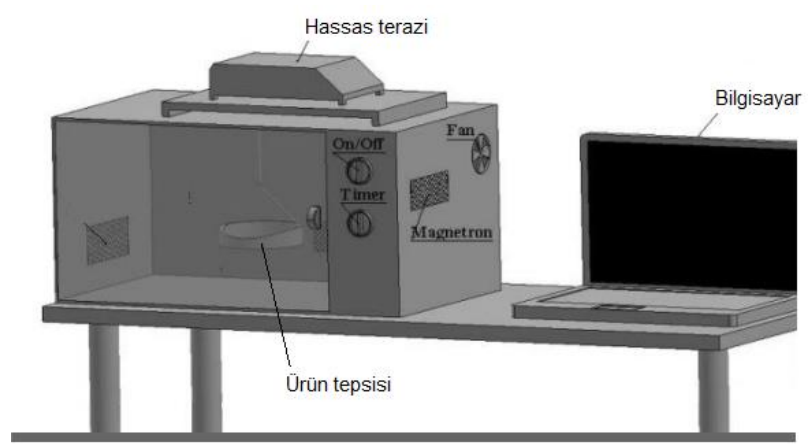

Şekil 2. Mikrodalga kurutma firını (Çelen ve ark., 2015)

Figure 2. Microwave drying oven (Çelen ve ark., 2015)

Çalışmada yaş ve kuru üzüm nem içeriklerinin belirlenmesinde Nüve marka EV 018 tipi vakumlu etüv kullanılmıştır. Renk analizlerinde Koniko-Minolta CM-5 cihazı kullanılmış ve L*, a*, b*, chroma ve hue değerleri belirlenmiştir. Elde edilen değerler kullanılarak kuru üzümlerin kahverengileşme endeksleri (BI) ve toplam renk değişimleri $(\Delta \mathrm{E})$ Eşitlik 1, 2 ve 3 yardımıyla hesaplanmıştır (Maskan, 2001).

$$
\begin{gathered}
B I=\frac{[100 \cdot(x-0,31)]}{0,17} \\
x=\frac{\left(a^{*}+1.75 x L^{*}\right.}{\left(5.645 x L^{*}+a^{*}-3,012 x b^{*}\right)}
\end{gathered}
$$




$$
\Delta E=\sqrt{\left(L_{o}^{*}-L^{*}\right)^{2}+\left(a_{o}^{*}-a^{*}\right)^{2}+\left(b_{o}^{*}-b^{*}\right)^{2}}
$$

Denemelerde pH değeri, yaş üzüm örnekleri parçalanıp süzülmesi ile elde edilen şıranın direkt olarak pH metre ile ölçülmesi esasıyla tespit edilmiştir. Kuru üzümler homojenizatörde karıştırılarak saf su ile muamele edilmiş ve direkt olarak pH metre ile ölçümleri yapılmıştır. Suda çözünür kuru madde (SÇKM) analizleri için; parçalanıp suyu çıkartılmış örneklerde el tipi refraktometre ile ölçüm yapılıp \% briks derecesi belirlenmiştir.

Toplam fenolik madde içerikleri Waterhouse (2002) tarafından bildirilen Folin-Ciocalteu metodu ile gallik asit eşdeğeri $(\mathrm{mg} / \mathrm{kg})$ cinsinden belirlenmiştir.

Kurutma denemeleri herhangi bir kimyasal önişlem olmaksızın gerçekleştirilmiştir. Sıcak havalı yöntemde kurutma denemeleri 50,60 ve $70{ }^{\circ} \mathrm{C}$ olmak üzere 3 farklı kurutma sıcaklığında ve $1 \mathrm{~m} \mathrm{~s}^{-1}$ hava hızında, mikrodalga yönteminin kullanıldığı kurutma denemeleri ise 180 ve $270 \mathrm{~W}$ güç seviyelerinde gerçekleştirilmiştir.

Kurutma sırasında üründen uzaklaştırılan nem miktarı Eşitlik 4 yardımıyla hesaplanmıştır (Jithinraj ve Karim, 2014) .

$$
\Delta W=W_{1} x \frac{N_{1}-N_{2}}{100-N_{2}}
$$

Bu eşitlikte;

$\Delta \mathrm{W}=$ Üründen uzaklaştırılan nem miktarı $(\mathrm{kg})$,

$\mathrm{W}_{1}=$ Ürünün kurumadan önceki ağırlığg $1(\mathrm{~kg})$,

$\mathrm{N}_{1}=$ Ürünün kurumadan önceki nemi (y.b.),

$\mathrm{N}_{2}=$ Ürünün kurumadan sonraki nemidir (y.b.).

Yaş üzüm örnekleri \%75 ilk nem değerinden \%20 son nem değerine düşene kadar olan kurutma sürecinde ortaya çıkan enerji tüketimi değerleri pano üzerindeki elektrik sayacından $\mathrm{kWh}$ cinsinden okunarak kaydedilmiştir. Her iki kurutma yönteminde kuruma eğrilerinin çıkarılması amacıyla ağırlık azalışları periyodik olarak ölçülerek kaydedilmiştir.

Mikrodalga ile kurutma yönteminde elde edilen ürünün karamelizasyon ve renk bozukluğu gibi sebeplerle gıda değerleri açısından sıcak hava ile kurutma yönteminden elde edilen ürünle karşıllaştırması yerine üründe olumsuz özelliklerin oluşmaya başladığı kırılma noktalarının saptanması hedeflenmiş olup renk özellikleri ve toplam fenolik madde içerikleri sadece yaş ürün ve sıcak hava yöntemi ile kurutulmuş örnekler için gerçekleştirilmiştir. Elektrikli sıcak hava fırını ve mikrodalga ile kurutma yöntemlerinde ortaya çıkan kurutma süresi ve enerji tüketim değerleri JMP paket programı kullanılarak karşılaştırılmıştır. Sıcak hava ile kurutma yönteminde farklı sıcaklıklar ile yapılan uygulamalardan elde edilen ürünün kalite açısından gıda değerleri karşılaştırmalı olarak incelenmiştir.

Üzüm örneklerinin kuruma davranışını ifade eden uygun modelin saptanması için Çizelge 1'de belirtilmiş olan 4 model denenmiştir. 
Çizelge 1. Gıda kurutma prosesinde kullanılan ince tabaka kurutma modelleri (Kutlu ve ark., 2015)

Table 1. Thin layer drying models used for food drying processes (Kutlu ve ark., 2015)

\begin{tabular}{lll}
\hline Modeller & Matematiksel Denklemler & Kaynaklar \\
\hline Henderson-Pabis & $M R=a \exp (-k t)$ & (Bengston ve ark.,1998) \\
Newton & $M R=\exp (-k t)$ & (Ayensu, 1997; Tiris ve ark., 1994) \\
Logaritmik & $M R=a \exp (-k t)+c$ & (Lahsasni ve ark., 2004) \\
Wang ve Singh & $M R=1+a t+b t^{2}$ & (Wang ve Singh, 1978) \\
\hline
\end{tabular}

Sicak havalı kurutma ve mikrodalga kurutma verilerine ilişkin parametreler deneysel olarak elde edilmiş olan sonuçların lineer olmayan regresyon analizi tekniği ile saptanmıştır. Bu analiz, Statistica 5.5 istatistik programını kullanılarak gerçekleştirilmiştir. Model parametrelerinin saptanması için Quasi-Newton nümerik metod kullanılmıştır. En uygun modelin seçilebilmesi için, analiz sonucunda bulunan tahmini değerlerden ve kalanlar verilerinden yararlanılarak khi-kare $\left(\chi^{2}\right)$, ortalama karesel hata (RMSE=root mean square error) ve model etkinliği (EF) değerleri hesaplanmıştır. En uygun model olarak, her uygulama için saptanan $\chi^{2}$ değerinin en düşük, RMSE değerinin sıfıra en yakın ve EF değerinin de en yüksek değerde olanı (model etkinliği için maksimum değer 1'dir) seçilmiştir. Bu kriterler aşağıdaki eşitliklerden yararlanılarak hesaplanmıştır (Ertekin ve Yaldız, 2004; Hossain ve Bala, 2002).

$$
\begin{gathered}
\chi^{2}=\frac{\sum_{i=1}^{N}\left(M_{\exp i}-M_{p r e, i}\right)^{2}}{N-n} \\
R M S E=\sqrt{\frac{\sum_{i=1}^{N}\left(M_{p r e, i}-M_{\exp i}\right)^{2}}{N}} \\
E F=\frac{\sum_{i=1}^{N}\left(M_{\exp i}-M_{i, \exp _{\text {mean }}}\right)^{2}-\sum_{i=1}^{N}\left(M_{p r e, i}-M_{\exp \dot{p}}\right)^{2}}{\sum_{i=1}^{N}\left(M_{\exp i}-M_{i, \exp _{\text {mean }}}\right)^{2}}
\end{gathered}
$$

Bu eşitliklerde, $M_{\text {exp }, i}$ i. deneysel denge nem içeriği, $M_{\text {pre, } i}$ i. tahmin edilen denge nem içeriği $N$ gözlem sayısı, $n$ kullanılan sorpsiyon modelindeki model sabiti sayısı ve $M_{\text {expmean }}$ ise deneysel ortalama denge nem içeriğidir.

\section{Bulgular ve Tartışma}

Sıcak havalı kurutmada, ilk nemi \%75 olan üzüm örnekleri $1 \mathrm{~m} \mathrm{~s}^{-1}$ hava hızı ve farklı kurutma sıcaklıklarında kurutulmuş ve üzüm örneklerinin \%20 nem düzeyine düşürülene kadarki nem içeriği değişimine yönelik grafik Şekil 3'de verilmiştir. 


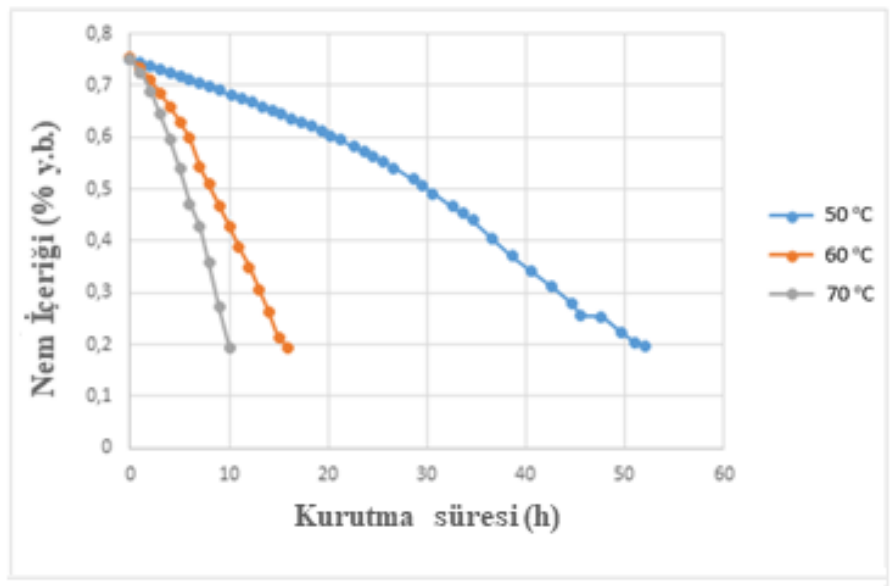

Şekil 3. Üzüm örneklerinin nem içeriklerinin farklı kurutma sıcaklıklarına bağlı olarak değişimi

Figure 3. Change of moisture contents of grape samples based on different drying temperatures

Şekil 3'de görüldüğü gibi sıcaklık artışı ile birlikte kurutma sürelerinde önemli düşüş meydana gelmiştir. Sıcak hava ile kurutma yönteminde üründeki nemin $\% 50$ 'si $50{ }^{\circ} \mathrm{C}$ sıcaklık değerinde kurutma sürecinin ilk \% 37,6'lık bölümünde, $60{ }^{\circ} \mathrm{C}$ sicaklık değerinde ilk \% 34,9'luk bölümünde ve $70{ }^{\circ} \mathrm{C}$ sicaklık değerinde ilk \% 35'lik dilimde uzaklaştırılmıştır. Her 3 sıcaklık değerinde kurutma süreleriyle birlikte ortaya çıkan enerji tüketim değerleri Şekil 4 ve Çizelge 2'de verilmiştir.

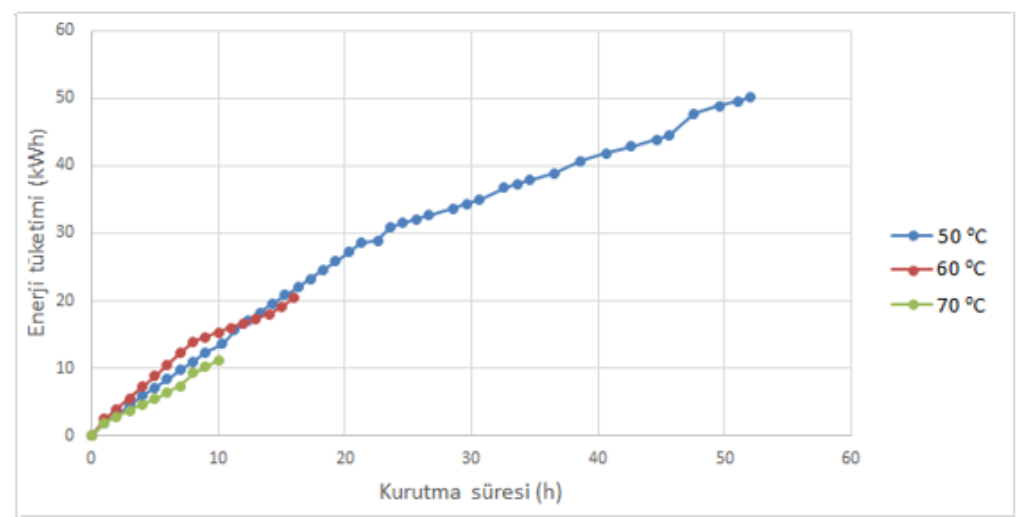

Şekil 4. Farklı sıcaklıklarda enerji tüketimlerinin değişimi

Figure 4. Change of energy consumption in different temperatures

Çizelge 2. Sıcak hava ile kurutma yönteminde kurutma süreleri ve enerji tüketimleri

Table 2. Drying time and energy consumptions in hot air drying method

\begin{tabular}{|c|c|c|c|}
\hline $\begin{array}{c}\text { Kurutma } \\
\text { sicaklığ }\left({ }^{\circ} \mathrm{C}\right)\end{array}$ & Ortalama örnek ağırlığı (g) & Kurutma süresi $^{*} \quad(\mathrm{~h})$ & Enerji tüketimi** $\left(\mathrm{kWh} \mathrm{kg}^{-1}\right)$ \\
\hline 50 & 202,46 & $49,53^{a}$ & $82,51^{\mathrm{a}}$ \\
\hline 60 & 222,33 & $15,16^{\mathrm{b}}$ & $30,82^{b}$ \\
\hline 70 & 195,08 & $10^{\mathrm{c}}$ & $19,15^{\mathrm{c}}$ \\
\hline
\end{tabular}

$\mathrm{LSD}=4,26^{*}(\mathrm{P}<0,05)$

$\mathrm{LSD}=0,94^{* *}(\mathrm{P}<0,05)$ 
Sıcaklık artışı ile birlikte kurutma süresindeki düşüşe bağlı olarak enerji tüketim değerleri için uygulanan LSD testine göre önemli düzeyde azalma görülmektedir. $50{ }^{\circ} \mathrm{C}$ 'de yapılan kurutma uygulamasında $82,51 \mathrm{kWh} \mathrm{kg}^{-1}$ düzeyinde enerji tüketimi ortaya çıkarken $70^{\circ} \mathrm{C}^{\prime}$ de bu değer $19,15 \mathrm{kWh} \mathrm{kg}^{-1}$ olarak ölçülmüştür.

Mikrodalga ile kurutma yönteminde üzüm örneklerinin nem içeriğinin \% 75'den \% 20'ye düşene kadar ortaya çıkan değişim Şekil 5'de gösterilmiştir. Bu yöntemde de güç seviyesinin artışı ile birlikte kurutma süresinde önemli düşüş oluştuğu görülmektedir.

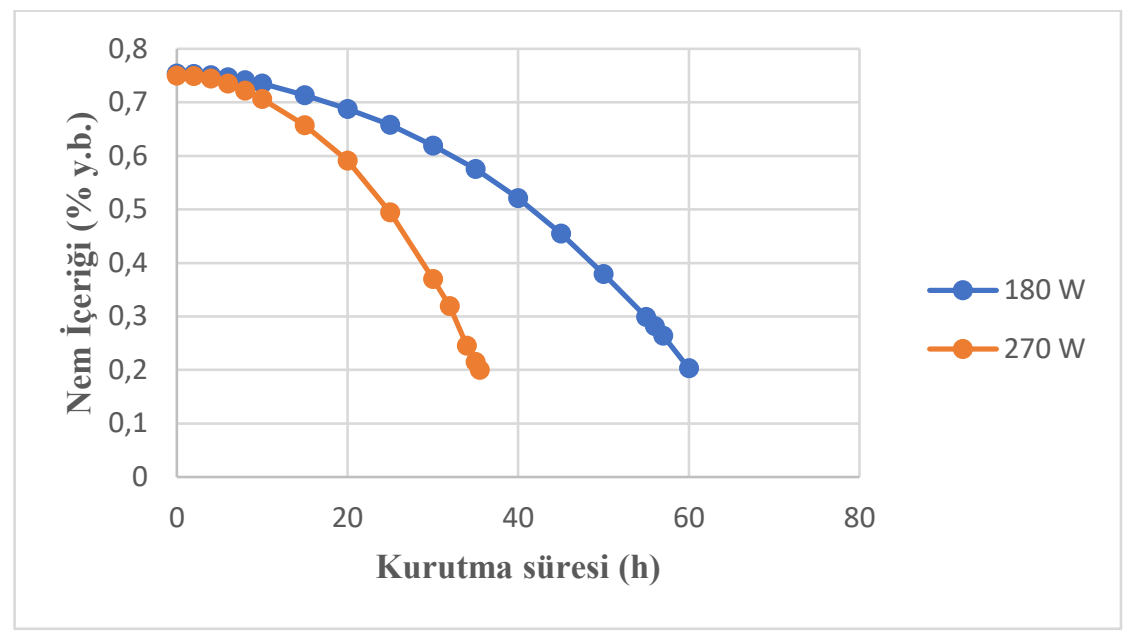

Şekil 5. Farklı mikrodalga güç seviyelerinde nem içeriğinin değişimi

Figure 5. Change of moisture content in different microwave power levels

Mikrodalga ile kurutma yönteminde güç seviyesinin artışı ile birlikte kurutma süresi azalmaktadır. Bu yöntemde üründeki nemin \% 50'si $180 \mathrm{~W}$ değerinde kurutma sürecinin ilk \% 40,6’l1k bölümünde, $270 \mathrm{~W}$ güç değerinde ilk \% 36,9'luk bölümünde uzaklaştırılmıştır. Mikrodalga ile kurutma yönteminde güç artışı ile birlikte ortaya çıkan kurutma süresi ve enerji tüketimi değerleri Şekil 6 ve Çizelge 3'de verilmiştir.

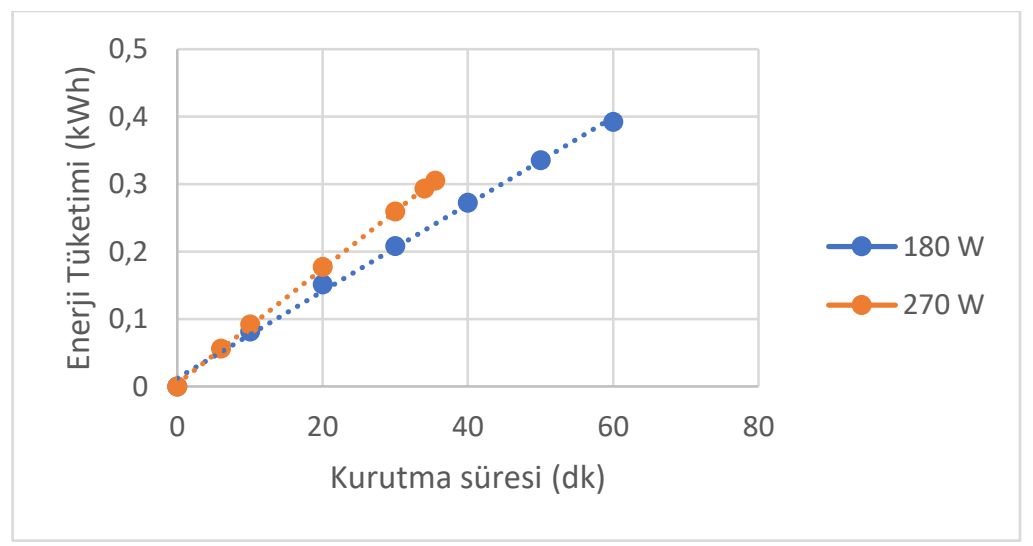

Şekil 6. Farklı mikrodalga güç seviyelerinde enerji tüketiminin değişimi

Figure 6. Change of energy consumption in different microwave power levels 
Çizelge 3. Farklı mikrodalga güç seviyelerinde kurutma süreleri ve enerji tüketimleri

Table 3. Drying time and energy consumptions in different microwave power levels

\begin{tabular}{cccc}
\hline Kurutma gücü $(\mathrm{W})$ & Örnek ağırlığı $(\mathrm{g})$ & Kurutma süresi (min) & Enerji tüketimi (kWh kg-1) \\
180 & 200,5 & 60 & 1,95 \\
270 & 200,2 & 35,5 & 1,52 \\
\hline
\end{tabular}

Mikrodalga ile kurutma yönteminde de sıcak hava ile kurutma uygulamasında olduğu gibi uygulama güç seviyesi yükseldiğinde kurutma süresindeki kısalmaya bağlı olarak enerji tüketimi de azalmıştır. Bu yöntemde uygulanan mikrodalga gücü ile ürün miktarı arasında önemli bir ilişki olduğu görülmüştür. Yapılan ön denemelerde aynı güç değerinde 16,5 g üzüm örneğinden alınan sonuçlar ile $200 \mathrm{~g}$ ürün örneğinden alınan sonuçlar önemli farklılıklar göstermiştir. Örneğin $90 \mathrm{~W}$ güç değerinde $16,5 \mathrm{~g}$ üzüm örneğinde ürün nemi 1 h'lik kurutma periyodunda \%75'den \%29'a kadar herhangi bir renk bozukluğu olmaksızın ulaşırken ürün miktarı $200 \mathrm{~g}$ değerine çıktığında bu güç değeri yetersiz kalmıştır.

Sıcak havalı kurutma yönteminde yapılan denemelerde farklı sıcaklıklarda elde edilen ürünün gıda değerleri açısından yapılan analizlerinde renk değişimi ve toplam fenolik madde içerikleri belirlenerek Çizelge 4 ve 5 'te verilmiştir.

Çizelge 4. Farklı kurutma sıcaklıklarında tespit edilen toplam fenolik madde miktarlarındaki değişim

Table 4. Change in total phenolic content determined in different drying temperatures

\begin{tabular}{cc} 
Table 4. Change in total phenolic content determined in different drying temperatures \\
\hline Kurutma sıcaklığı $\left({ }^{\circ} \mathrm{C}\right)$ & Toplam Fenolik Madde Miktarı $(\mathrm{mg} / \mathrm{kg} \mathrm{GAE})$ \\
\hline Taze üzüm örneği & 450 \\
50 & $1618^{\mathrm{b}}$ \\
60 & $2261^{\mathrm{b}}$ \\
70 & $4884^{\mathrm{a}}$ \\
\hline
\end{tabular}

$\mathrm{LSD}=719,2(\mathrm{P}<0,05)$

Sıcaklıkla toplam fenolik madde miktarının değişimi için uygulanan LSD testi sonucuna göre sıcaklık artışı ile birlikte son üründeki toplam fenolik madde miktarı yükselmiştir. Bazı araștırmacılar (Maillard ve ark., 1996; Manzocco ve ark., 1998; Karadeniz ve ark., 2000; Jimenez ve ark., 2002; Meng ve ark., 2008; SánchezGonzález ve ark., 2011; Ferreira-Lima ve ark., 2013) maillard reaksiyonu, enzimatik esmerleşme ve oksidasyon olaylarıyla antioksidan aktivite gösteren yeni bileşiklerin ortaya çıktığını bildirmiştir. Geleneksel yöntemle üretilen pekmezlerde toplam fenolik ve antioksidan aktivitenin daha yüksek değerler (yaklaşık 2-3 kat) aldığ1 görülmüş, bu durumun maillard, esmerleşme, oksidasyon vb. reaksiyonlar sonucu oluşan fenolik maddelerin kondanse formları ve bazı yeni bileşiklerden kaynaklandığı sonucuna varılmıştır (Gülcü, 2016). Çizelge 5'te görüldüğü üzere sıcaklık arttıkça kahverengileşme indeksinin artması, sıcaklığın yükselmesiyle birlikte kuru üzümlerin renklerinin esmerleştiğini göstermektedir.

Çizelge 5. Farklı sıcaklıklarda kurutulan üzümlerin renk değerlerindeki değişimler

Table 5. Change in color of grapes dried in different temperatures

\begin{tabular}{ccccc}
\multicolumn{6}{c}{ Table 5. Change in color of grapes dried in different temperatures } & \\
$\begin{array}{c}\text { Kurutma } \\
\text { sicaklı̆̆ }\left({ }^{\circ} \mathrm{C}\right)\end{array}$ & $\mathrm{L}^{*}$ & $\mathrm{a}^{* *}$ & $\mathrm{~b}^{* * *}$ & Kahverengileşme indeksi $^{* * * *}(\mathrm{BI})$ \\
\hline $\begin{array}{c}\text { Taze üzüm } \\
\text { örneği }\end{array}$ & 38,43 & $-1,25$ & 6,18 & - \\
50 & $28,19^{\mathrm{b}}$ & $5,31^{\mathrm{c}}$ & $6,11^{\mathrm{c}}$ & $37,79^{\mathrm{c}}$ \\
60 & $31,40^{\mathrm{a}}$ & $8,39^{\mathrm{b}}$ & $13,87^{\mathrm{b}}$ & $76,64^{\mathrm{b}}$ \\
70 & $30,89^{\mathrm{a}}$ & $9,64^{\mathrm{a}}$ & $15,84^{\mathrm{a}}$ & $92,53^{\mathrm{a}}$ \\
\hline
\end{tabular}

$\mathrm{LSD}=1,27^{*}(\mathrm{P}<0,05) \quad \mathrm{LSD}=0,33^{* *}(\mathrm{P}<0,05) \quad \mathrm{LSD}=0,47^{* * *}(\mathrm{P}<0,05) \quad \mathrm{LSD}=3,46^{* * * *}(\mathrm{P}<0,05)$

Çizelge 3, 4 ve 5'de sunulmuş ve LSD testi ile değerlendirilmiş olan sonuçlar, kurutma süresi ve enerji tüketimi değerlerinde olduğu gibi uygulanan sıcaklık değerinin değişiminin, toplam fenolik madde miktarları ve renk değişimleri üzerinde de önemli etkiye sahip olduğunu göstermiştir.

Çizelge 6'da sıcak havalı kurutma ve mikrodalga kurutma yöntemleri için Sultani Çekirdeksiz üzüm çeşidinin kuruma davranışına uygun modelin saptanması için kullanılan ince tabaka modelleri ve bu modellere 
JOTAF/ Journal of Tekirdag Agricultural Faculty, 2020, 17(1)

ilişkin model parametreleri verilmiştir. Çizelge 6 incelendiğinde üzümün hem sıcak havalı yöntemle kurutulmasında hem de mikrodalga sisteminde kurutulmasında kuruma davranışına ilişkin EF, RMSE ve $\chi 2$ sonuçlarının birlikte değerlendirilme sonucunda uygun modelin Wang ve Singh modeli olduğu görülmektedir.

\section{Çizelge 6. Sultani çekirdeksiz üzüm örnekleri için farklı kurutma yöntem ve şartlarında analiz edilen} modellere ilişkin parametreler

Table 6. Parameters in models analysed in different drying method and conditions for Sultana seedless grape samples

\begin{tabular}{|c|c|c|c|c|c|c|}
\hline Model & $\begin{array}{l}\text { Kurutma } \\
\text { yöntemi }\end{array}$ & $\begin{array}{c}\text { Sicaklık/Mikrodalga güç } \\
\text { seviyesi }\end{array}$ & Model sabitleri & $\mathrm{EF}$ & RMSE & $\chi^{2}$ \\
\hline \multirow[t]{5}{*}{ Henderson-Pabis } & $\begin{array}{c}\text { Sicak havalı } \\
\text { kurutma }\end{array}$ & $50^{\circ} \mathrm{C}$ & $\begin{array}{l}\text { a: } 1,0957 \\
\text { k: } 0,0194\end{array}$ & 0,9131 & 0,4284 & 0,0045 \\
\hline & & $60^{\circ} \mathrm{C}$ & $\begin{array}{l}\text { a: } 1,0976 \\
\text { k: } 0,0708\end{array}$ & 0,9438 & 0,2365 & 0,0037 \\
\hline & & $70^{\circ} \mathrm{C}$ & $\begin{array}{l}\text { a: } 1,0907 \\
\text { k: } 0,1020\end{array}$ & 0,9235 & 0,2185 & 0,0053 \\
\hline & $\begin{array}{c}\text { Mikrodalga } \\
\text { kurutma }\end{array}$ & $180 \mathrm{~W}$ & $\begin{array}{l}\text { a: } 1,1063 \\
\text { k: } 0,0152\end{array}$ & 0,8771 & 0,3800 & 0,0090 \\
\hline & & $270 \mathrm{~W}$ & $\begin{array}{l}\text { a: } 1,1302 \\
\text { k: } 0,0283\end{array}$ & 0,8785 & 0,3696 & 0,0114 \\
\hline \multirow[t]{5}{*}{ Logaritmik } & $\begin{array}{c}\text { Sicak havalı } \\
\text { kurutma }\end{array}$ & $50^{\circ} \mathrm{C}$ & $\begin{array}{c}\text { a: } 38,7413 \\
\mathrm{k}: 0,0004 \\
\mathrm{c}:-37,6781\end{array}$ & 0,9731 & 0,2384 & 0,0014 \\
\hline & & $60^{\circ} \mathrm{C}$ & $\begin{array}{c}\mathrm{a}: 78,2758 \\
\mathrm{k}: 0,0006 \\
\mathrm{c}:-77,2237\end{array}$ & 0,9915 & 0,0921 & 0,0007 \\
\hline & & $70^{\circ} \mathrm{C}$ & $\begin{array}{c}\mathrm{a}: 157,4284 \\
\mathrm{k}: 0,0005 \\
\mathrm{c}:-156,359\end{array}$ & 0,9819 & 0,1094 & 0,0015 \\
\hline & $\begin{array}{c}\text { Mikrodalga } \\
\text { kurutma }\end{array}$ & $180 \mathrm{~W}$ & $\begin{array}{c}\mathrm{a}: 35,7188 \\
\mathrm{k}: 0,0003 \\
\mathrm{c}:-34,6290\end{array}$ & 0,9391 & 0,2676 & 0,0048 \\
\hline & & $270 \mathrm{~W}$ & $\begin{array}{c}\mathrm{a}: 59,9723 \\
\mathrm{k}: 0,0004 \\
\mathrm{c}:-58,8670\end{array}$ & 0,9438 & 0,2513 & 0,0057 \\
\hline \multirow[t]{5}{*}{ Newton Modeli } & $\begin{array}{l}\text { Sicak havalı } \\
\text { kurutma }\end{array}$ & $50^{\circ} \mathrm{C}$ & k: 0,0161 & 0,8741 & 0,5160 & 0,0063 \\
\hline & & $60^{\circ} \mathrm{C}$ & $\mathrm{k}: 0,0607$ & 0,9130 & 0,2942 & 0,0054 \\
\hline & & $70^{\circ} \mathrm{C}$ & $\mathrm{k}: 0,0875$ & 0,8928 & 0,2586 & 0,0067 \\
\hline & Mikrodalga & $180 \mathrm{~W}$ & k: 0,0125 & 0,8293 & 0,4479 & 0,0118 \\
\hline & & $270 \mathrm{~W}$ & $\mathrm{k}: 0,0231$ & 0,8243 & 0,4444 & 0,0152 \\
\hline \multirow[t]{5}{*}{ Wang ve Singh } & $\begin{array}{c}\text { Sicak havalı } \\
\text { kurutma }\end{array}$ & $50^{\circ} \mathrm{C}$ & $\begin{array}{l}\text { a: }-0,0067 \\
\text { b: }-0,0002\end{array}$ & 0,9977 & 0,0698 & 0,0001 \\
\hline & & $60^{\circ} \mathrm{C}$ & $\begin{array}{l}\text { a: }-0,0313 \\
\text { b: }-0,0010\end{array}$ & 0,9968 & 0,0566 & 0,0002 \\
\hline & & $70{ }^{\circ} \mathrm{C}$ & $\begin{array}{l}\text { a: }-0,0363 \\
\text { b: }-0,0038\end{array}$ & 0,9990 & 0,0256 & 0,0001 \\
\hline & $\begin{array}{l}\text { Mikrodalga } \\
\text { kurutma }\end{array}$ & $180 \mathrm{~W}$ & $\begin{array}{l}\text { a: } 0,00004 \\
\text { b: }-0,0002\end{array}$ & 0,9995 & 0,239 & 0,00003 \\
\hline & & $270 \mathrm{~W}$ & $\begin{array}{l}\text { a: } 0,0013 \\
\text { b: }-0,0006\end{array}$ & 0,9993 & 0,0271 & 0,0001 \\
\hline
\end{tabular}




\section{Sonuç ve Öneriler}

Yapılan çalışmada Sultani Çekirdeksiz üzüm çeşidini kurutmada, sıcak havalı ve mikrodalga yöntemleri olmak üzere uygulanmış olan iki farklı kurutma yönteminin, kurutma süresi, enerji tüketimi ve bazı ürün kalite özellikler üzerine etkileri incelenmiş olup; sıcak hava yöntemi ile yapılan uygulamada sıcaklık artışının kurutma süresi ve enerji tüketimini önemli ölçüde düşürdüğü belirlenmiştir. Ancak elde edilen son üründe fenolik madde miktarları ve kahverengileşme indeksi değerleri yükselmiştir. Fenolik madde miktarındaki artışın sıcaklığın yükselmesiyle birlikte maillard reaksiyonu, enzimatik esmerleşme ve oksidasyon olaylarıyla oluşan yeni bileşiklerden kaynaklandığı düşünülebilir.

Mikrodalga ile kurutma yönteminde ise güç seviyesinin artı̧̧ ile kurutma süresi ve enerji tüketimi değerlerinde düşü̧s gerçekleşirken son üründe karamelizasyon ile birlikte kavrulma, renk bozukluğu gibi olumsuz özelliklerle karşılaşılmıştır. Ancak kurutma sürecinin \%70-75' lik bölümünde herhangi bir olumsuzluk gözlenmemiştir. Kurutma süresi, enerji tüketimi ve elde edilen son ürünün kalitesi göz önünde bulundurulduğunda bu sonuç üzüm kurutma amaciyla mikrodalga ile kurutma yönteminin tekil olarak kullanımından ziyade diğer kurutma yöntemlerinden biriyle kombine olarak kullanımın daha etkin ve ekonomik bir çözüm sunabileceğini göstermektedir.

Mikrodalga ile kurutma yönteminde üründe bozulmaların başlamaya başladığı noktadaki ürün nem oranı \%45-50 seviyesinde saptanmıştır. Bu değer üzüm kurutma uygulamasında kombine sistem kullanımında bir kırılma noktası olarak değerlendirilebilir. Bu yöntemde yapılan ön deneme sonuçları uygulama gücü ile kurutulacak ürün miktarı arasında önemli bir ilişki olduğunu göstermiştir.

Alınan tüm sonuçlar birlikte değerlendirildiğinde farklı kurutma yöntemlerinin birlikte kullanımında hangi yöntemin hangi sırayla ve ne ölçüde süreçte yer alacağının önem taşıdığı anlaşılmaktadır. Ön işlemsiz şartlarda Sultani Çekirdeksiz üzüm çeşidinin kurutulmasında ürünün $\% 45$ nem düzeyine kadar mikrodalga yöntemi ve kalan nemin sıcak hava ile kurutma yöntemiyle tamamlanması şeklinde uygulanabileceği görülmektedir.

Analiz edilen 4 ince tabaka kurutma modeli arasında Wang ve Sing modelinin, Sultani Çekirdeksiz üzüm çeşidinin hem sıcak havalı yöntemle hem de mikrodalga yöntemi ile kurutulması sırasında bu ürünün kurutma karakteristiklerini en iyi temsil eden model olduğu saptanmıştır. 


\section{Kaynakça/References}

Almeida, I., Guine, R.P.F., Gonçalves, F. \& Correia, C. (2013). Comparison of drying processes for the production of raisins from a seedless variety of grapes, International Conference On Engineering, Portugal.

Ayensu, A. (1997). Dehydration of food crops using a solar dryer with convective heat flow, Solar Energy 59 (4-6):121-126.

Bengston, G., Rahman, M.S., Stanley, R. \& Perera, C.O. (1998). Effect specific pretreatment on the drying behavior of apple rings. New Zeland Inst. of Food Science and New Zeland Conference, Nelson, 10s.

Çelen, S., Aktaş, T., Karabeyoğlu, S.S. \& Akyıldız, A. (2015). Zeytin pirinasının mikrodalga enerjisi kullanılarak kurutulması ve uygun ince tabaka modelinin belirlenmesi. Tekirdă̆ Ziraat Fakültesi Dergisi. 12 (02): 21-31.

Ertekin, C. \& Yaldiz, O. (2004). Drying of eggplant and selection of a suitable thin layer drying model. J Food Eng, 63, 349-359.

Ferreira-Lima, N.E., Burin, V.M. \& Bordignon-Luiz, M.T. (2013). Characterization of Goethe white wines: influence of different storage conditions on the wine evolution during bottle aging. European Food Research and Technology, 237(4): 509-520.

Gülcü, M. (2016). The effect of production process and storage conditions of resveratrol and bioactive characteristics of some grape varieties (Doctoral dissertation, PhD thesis, Namık Kemal University Graduate School of Natural and Applied Sciences, Tekirdağ, Turkey.

Hossain, M.A. \& Bala, B.K. (2002). Thin-layer drying characteristics for green chilli. Drying Technology, 20(2): $489-505$.

Jimenez, A., Creissen, G., Kular, B., Firmin, J., Robinson, S., Verhoeyen, M. \& Mullineaux, P. (2002). Changes in oxidative processes and components of the antioxidant system during tomato fruit ripening. Planta, 214(5): 751-758.

Jithinraj, T. \& Karim, A.A. (2014). Experimental analysis on multi pass flat plate collector solar air dryer. International Journal of Emerging Engineering Research and Technology, (2):1-11.

Karaaslan, S., Ekinci, K. \& Akbolat, D. (2017). Drying characteristics of sultana grape fruit in microwave dryer, Infrastructure And Ecology Of Rural Areas, 1, 1317-1327.

Karadeniz, F., Durst, R.W. \& Wrolstad, R.E. (2000). Polyphenolic composition of raisins. Journal of Agricultural and Food Chemistry, 48(11): 5343-5350.

Kassem, A.S., Shokr, A.Z., El-Mahdy, A.R., Aboukarima, A.M. \& Hamed, E.Y. (2011). Comparison of drying characteristics of Thompson seedless grapes using combined microwave oven and hot air drying, Journal of the Saudi Society of Agricultural Sciences, 10, 33-40.

Kutlu, N., İşçi, A., Şakıyan Demirkol, Ö. (2015). Gıdalarda ince tabaka kurutma modelleri, Gıda, 40 (1): 39-46.

Lahsasni, S., Kouhila, M., Mahrouz, M. \& Jaouhari, J.T. (2004). Drying kinetics of prickly pear fruit (Opuntica ficus indica ), Journal of Food Engineering, 61(2): 173-179.

Maillard, M.N., Soum, M.H., Boivin, P. \& Berset, C. (1996). Antioxidant activity of barley and malt: relationship with phenolic content. LWTFood Science and Technology, 29(3): 238-244.

Manzocco, L., Mastrocola, D. \& Nicoli, M.C. (1998). Chain-breaking and oxygen scavenging properties of wine as affected by some technological procedures. Food research international, 31(9): 673-678.

Maskan, M. (2001). Drying, shrinkage and rehydration characteristics of kiwifruits during hot air and microwave drying. Journal of Food Engineering, 48, 177-182.

Meng, X., Li, B., Liu, J. \& Tian, S. (2008). Physiological responses and quality attributes of table grape fruit to chitosan preharvest spray and postharvest coating during storage. Food Chemistry, 106(2): 501-508.

Sánchez-González L, Pastor C, Vargas M, Chiralt A, González-Martínez C, Cháfer M (2011). Effect of hydroxypropylmethylcellulose and chitosan coatings with and without bergamot essential oil on quality and safety of cold-stored grapes. Postharvest Biology and Technology, 60(1): 57-63.

Tarhan, S., Ergüneş, G. \& Tekelioğlu, O. (2007). Tarımsal ürünler için güneş enerjili kurutucuların tasarım ve işletme esasları, Tesisat Mühendisliği Dergisi, 99, 26-32.

Tiris, C., Ozbalta, N., Tiris, M. \& Dincer, I. (1994). Experimental testing of new solar dryer, International Journal of Energy Reasarch, 18, 483-490.

Wang, C.Y. \& Singh, R.P. (1978). A single layer drying equation for rough rice ASAE ss. 78-3001, ASAE, St. Joseph, MI.

Waterhouse, A.L. (2002). Determination of total phenolics. Current protocols in food analytical chemistry. 